\title{
Excitatory backward conditioning of defensive burying in rats
}

\author{
MARICA L. SPETCH, LORI J. TERLECKI, JOHN P. J. PINEL, \\ DONALD M. WILKIE, and DALLAS TREIT \\ University of British Columbia, Vancouver, British Columbia V6T 1W5, Canada
}

\begin{abstract}
Rats received six backward US-CS pairings; $1 \mathrm{sec}$ after the termination of each of six 120msec shocks to the rat's back, a 7-cm metal prod was inserted through a hole in one wall of the chamber for $5 \mathrm{sec}$. During the subsequent test, these rats spent as much time burying the prod CS with bedding from the floor of the chamber as did rats receiving six forward prod-shock pairings, and significantly more time than did those in unpaired, shock-only, or prod-only control groups.
\end{abstract}

The authenticity of backward conditioning continues to be a controversial issue within the animal learning literature. Although there is some experimental evidence that excitatory backward conditioning may be a legitimate associative phenomenon (Heth \& Rescorla, 1973; Keith-Lucas \& Guttman, 1975; Mahoney \& Ayres, 1976; Shurtleff \& Ayres, 1981; Wagner \& Terry, 1975), the widespread belief that genuine excitatory conditioning does not occur when the unconditioned stimulus (US) precedes the conditioned stimulus (CS) (cf. Gormezano \& Moore, 1969; Kimble, 1961; Mackintosh, 1974; Schwartz, 1978; Terrace, 1973) has continued to flourish. The importance of this issue stems from the fact that the possibility of excitatory backward conditioning is incompatible with most existing theories of classical conditioning (e.g., Bolles, 1972; Hull, 1943; Rescorla, 1967; Rescorla \& Wagner, 1972). For example, many views of conditioning assume that a CS acquires excitatory properties because of its predictive relationship with a US (e.g., Bolles, 1972, 1978; Rescorla, 1967). Because a backward CS predicts the absence rather than the presence of the US, it should not acquire excitatory properties, according to these views.

We investigated excitatory backward conditioning in a modification of the conditioned defensive burying paradigm developed by Pinel and Treit (1978). They demonstrated that rats shocked once through a stationary wire-wrapped prod mounted on the chamber wall returned to the prod and buried it (i.e., sprayed bedding material from the chamber floor toward and over it). Almost all rats shocked in this way spent some time

This research was supported by Natural Science and Engineering Research Council of Canada scholarships (to M. L. Spetch, L. J. Terlecki, and D. Treit) and operating grants (to J. P. J. Pinel and D. M. Wilkie). The authors are grateful to D. S. Gray and R. W. Skelton for their helpful comments and suggestions. Address reprint requests to D. M. Wilkie at the University of British Columbia, Psychology Department, 2075 Wesbrook Mall, Vancouver, British Columbia V6T 1W5, Canada. burying the prod when tested a short time later, and significant amounts of burying were observed even when rats were tested 20 days after the single conditioning trial. Evidence that the burying behavior was the result of associative learning was provided by a study in which all 10 rats shocked by one of two identical prods selectively buried the shock prod.

Because the aversive conditioning produced in the burying paradigm is rapid and reliable, the defensive burying paradigm seemed well suited for investigations of backward conditioning. In fact, Hudson (1950) had reported observing the burying response in a study involving a backward conditioning procedure. He shocked rats while they were eating and then dropped a bundle of pipe cleaners next to them. In a subsequent test, he noted that some rats pushed wood shavings toward the pipe cleaners. Unfortunately, Hudson did not include the control procedures necessary to rule out nonassociative interpretations of the effect.

In the present experiment, the standard burying paradigm was modified so that the presentation of the CS and US could be controlled by the experimenter. In the standard paradigm, rats are shocked a single time through a stationary prod when they contact it; in the present experiment, the shock US was administered several times through wound clips attached to the rat's back, and a retractable prod CS was inserted into the chamber at various times with respect to the shock delivery.

The burying behavior of rats in two conditioning groups was compared with that of rats in three control groups. Rats in one conditioning group, the backward group, received six backward pairings of the shock and prod. Rats in a second conditioning group, the forward group, received six forward pairings of the shock and the prod. This forward group was included to ensure that any burying that might occur following the backward shock-prod pairings was excitatory (i.e., a response qualitatively similar to that produced by forward pairings). 
The three additional groups served as controls for the possible nonassociative effects of exposure to the shock and prod. Rats in one control group, the unpaired group, received six presentations of the shock and prod in an unpaired manner. This explicitly unpaired control procedure was used instead of a "truly random control procedure" (Rescorla, 1967) because implementation of the latter procedure is inappropriate when so few conditioning trials are used (cf. Mahoney \& Ayres, 1976; Spetch, Wilkie, \& Pinel, 1981).

Rats in a second control group, the prod-only group, received six presentations of the prod without any shock presentations. This group served as a control for unconditioned burying. Although little unconditioned burying typically is directed at a stationary prod (i.e., prod burying by unshocked, habituated rats is rare), certain novel objects such as mousetraps and flashbulbs can elicit substantial amounts of unconditioned burying (Terlecki, Pinel, \& Treit, 1979). Thus, it seemed possible that a prod that moved in and out of the chamber also might elicit considerable amounts of unconditioned burying.

Finally, a shock-only group was included as a control for any nonassociative effects of exposure to presentations of the shock alone on subsequent burying of the prod.

\section{METHOD}

\section{Subjects}

The subjects were 60 naive male adult hooded rats purchased from Canadian Breeding Farm and Laboratories, La Prairie, Quebec. The rats were housed in individual wire-mesh cages in which Purina laboratory pellets and water were available continuously.

\section{Surgical Preparation and Habituation}

All rats were anesthetized with ethyl ether, and an area of approximately $4 \mathrm{~cm}^{2}$ on the rat's back just behind the neck was shaved of fur. Two 9-mm stainless steel wound clips (Clay Adams, Inc., N.Y.) were then attached (approximately $2 \mathrm{~cm}$ apart) to the exposed skin between the rats' shoulders.

Following implantation of the wound clips, the rats were habituated individually to the testing situation for a $30-\mathrm{min}$ period on each of 4 consecutive days. Prior to the commencement of each habituation session, hook-up wires (Belden, 20 AWG) were attached with alligator clips to the wound clips on the rat's back. The rat was then placed in the test chamber, a $41 \times 42 \times 48 \mathrm{~cm}$ black wooden box, the floor of which was covered with $8 \mathrm{~cm}$ of commercial bedding (San-I-Cel). The wires attached to the rat's back were suspended from above so as not to impede the movement of the rat about the chamber.

\section{Conditioning}

On the day following the last habituation session (Day 5), the rats were randomly assigned to one of five groups: the backward group $(n=12)$, the forward group $(n=12)$, the unpaired group $(n=12)$, the prod-only group $(n=12)$, and the shock-only group $(n=12)$. Each rat then was exposed to a single conditioning session, which consisted of presentations of a US and a CS. The US was a $120-\mathrm{msec}, 3-\mathrm{mA}, 60-\mathrm{Hz}$ sine-wave shock to the back of the animal delivered from a constantcurrent shocker. The CS was the presence in the chamber of a retractable black metal prod $(7 \mathrm{~cm}$ long and $.5 \mathrm{~cm}$ in diameter) that was inserted manually through a hole $(1 \mathrm{~cm}$ in diameter) centered on one wall of the test chamber, $3 \mathrm{~cm}$ above the bedding material. The temporal arrangements of the CS and/or US presentations for the five groups were the following.

Backward group. The conditioning session for rats in this group consisted of six trials in which the US and the CS were presented in a backward-paired fashion. The six trials occurred according to a variable-time schedule: For each animal, the first trial occurred $5 \mathrm{~min}$ after the beginning of the session and the six trials were separated by intervals of $2,4,3,1$, and $3 \mathrm{~min}$, respectively. Each trial began with the presentation of the $120-\mathrm{msec}$ shock. One second after the offset of the shock, the prod was inserted into the chamber. On each of the first five trials, the prod was then retracted after a $5-\sec$ CS period (from the end of insertion to the beginning of retraction). On the sixth trial, the prod remained in the chamber for $2 \mathrm{~min}$ before each rat was removed from the chamber.

Forward group. Each rat in this group received six trials in which the CS and US were presented in a forward-paired fashion. The trials occurred according to the same variable-time schedule used for the backward group. Each of the first five trials began with the insertion of the prod into the chamber for a $5-\mathrm{sec}$ period. Three seconds after the prod had been inserted, the $120-\mathrm{msec}$ shock was presented. The prod was then retracted at the end of the 5 -sec period $(1.88 \mathrm{sec}$ after the offset of the shock). The sixth trial was identical to the first five trials, except that the prod was not retracted after the 5-sec period; as in the backward group, it remained in the chamber for the final $2 \mathrm{~min}$ of the conditioning session.

Unpaired group. Each rat in this group received six unpaired presentations of the shock and the prod. The six shock presentations occurred according to the same variable-time schedule used in the backward and forward groups. The first prod presentation occurred 2 min after the beginning of the session, and the six prod presentations were separated by intervals of $4,3,1,6$, and $3 \mathrm{~min}$, respectively. As in the other groups, each of the first five prod presentations lasted for $5 \mathrm{sec}$, whereas the sixth presentation lasted for the final $2 \mathrm{~min}$ of the session.

Prod-only group. The "conditioning" session for rats in this group was identical to that of the backward group except that the shock presentations were omitted. Thus, each rat received five 5 -sec presentations of the prod, followed by a sixth prod presentation that lasted for the final $2 \mathrm{~min}$.

Shock-only group. Rats in this group received six presentations of the shock alone that occurred according to the variabletime schedule of trial presentations arranged for the backward group. One minute following the sixth shock, the prod was presented for the first time and left in the chamber for the final $2 \mathrm{~min}$ of the session.

Although the behavior of rats in each of the five groups was not systematically quantified during the "conditioning" sessions, it should be noted that at no time did any of the rats spray the bedding material toward the prod (i.e., bury). The most noticeable effect observed during the conditioning sessions was the general inactivity of the rats that received shocks compared with rats that did not.

\section{Testing}

Upon termination of the conditioning session, each rat was removed from the chamber, and the hookup wire was detached. In preparation for testing, the San-I-Cel in the test chamber was leveled, and the prod was inserted and attached to the wall of the chamber. The rat was placed back in the chamber after $5 \mathrm{~min}$, and a 40-min test session began. During the test session, the rat's behavior was viewed through a television camera mounted $120-\mathrm{cm}$ above the chamber, and the amount of time the rat spent burying (i.e., displacing the material toward the prod with forward pushing or spraying movements of its fore- 
paws) was recorded on an event recorder. Correlations between the scores of independent observers during test sessions comparable to the present ones have been reported to be exceptionally high-.988 (Pinel, Treit, \& Wilkie, 1980) and .93 (Davis \& Rossheim, 1980), for example.

\section{RESULTS}

Figure 1 shows the mean duration of burying by rats in each of the five conditions. Rats in both the backward and the forward conditioning groups spent substantially more time pushing bedding toward the prod than did rats in any of the three control groups. The significance of these differences was established by an analysis of variance for independent measures $[F(4,55)=7.15$, $\mathrm{p}<.05]$ and a subsequent Newman-Keuls test for post hoc pairwise comparisons $(p<.05)$. Significantly more burying was exhibited by rats in the forward $($ mean $=79.4 \mathrm{sec})$ and backward (mean $=90.8 \mathrm{sec})$ groups than by rats in the unpaired (mean $=12.1 \mathrm{sec}$ ), the shock-only (mean $=7.5 \mathrm{sec}$ ), or the prod-only $($ mean $=35.5 \mathrm{sec})$ control groups. There were no significant differences in time spent burying between rats in the forward and backward groups or between the rats in the three control groups.

\section{DISCUSSION}

These results confirm those of recent experiments (e.g., Heth \& Rescorla, 1973; Mahoney \& Ayres, 1976) in demonstrating that the excitatory effects of a few backward pairings exceed those produced by nonassociative control conditions. Some authors (e.g., Catania, 1979; Mackintosh, 1974) have been hesitant to view backward conditioning as a true condi-

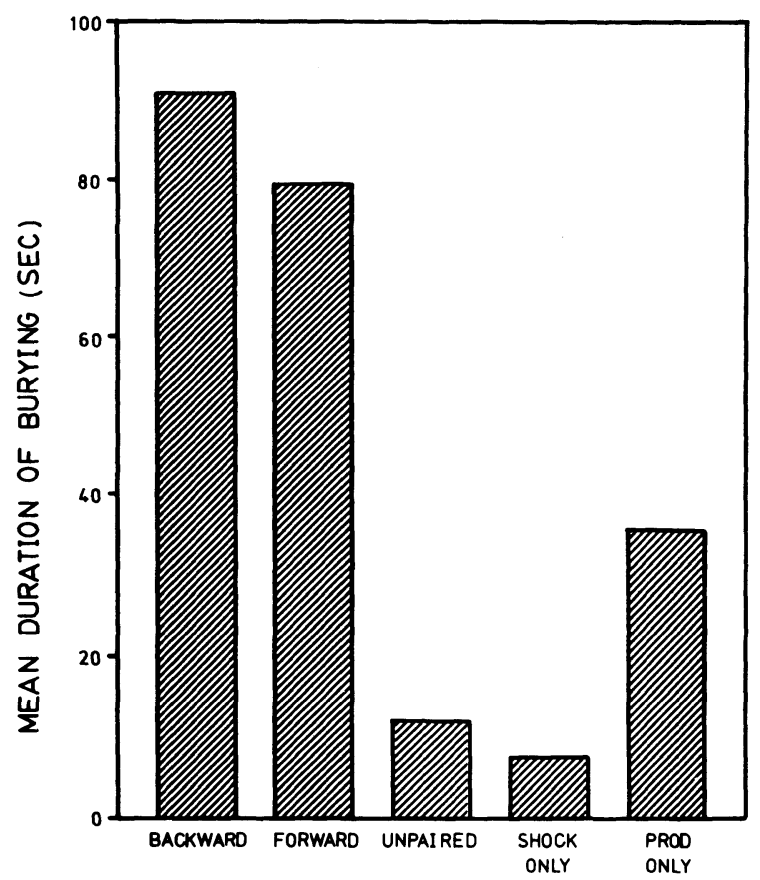

Figure 1. Mean duration of burying for subjects in the backward, forward, unpaired, shock-only, and prod-only groups. tioning process because of their belief that the excitatory effects of backward conditioning are unreliable and weak relative to those produced by forward conditioning. Our results and those of Keith-Lucas and Guttman (1975) have shown that this is not always the case. In the present experiment, backward conditioning was as robust as the conditioning produced by forward pairings. Keith-Lucas and Guttman attributed their success in obtaining robust backward conditioning to their use of a complex CS (a toy hedgehog) that perhaps resembled a natural predator of the rat, and they suggested that the backward conditioning reflected "an evolved capacity of the rat and many similar species to associate certain classes of stimulus objects with exteroceptive pain" $(1975$, p. 475). Accordingly, one might speculate that our use of a CS that moved in and out of the chamber may have contributed to the robustness of the backward conditioning seen in the present experiments.

Although excitatory backward conditioning is incompatible with most existing theories of classical conditioning, it can be understood readily from an ecological perspective (cf. KeithLucas \& Guttman, 1975; Spetch et al., 1981). The process that mediates backward conditioning may have evolved as an adaptation to surprise attacks by conspecifics or predators: An animal that could associate sudden aversive stimulation with the subsequent appearance of a novel stimulus and respond defensively would gain clear reproductive advantage. Consistent with this view is the fact that large backward conditioning effects were observed in the present experiment after only a few trials. In natural settings, animals that do not learn the relationship between a CS and a noxious US in a few trials are unlikely to stay alive to complete subsequent trials (Bolles, 1970).

\section{REFERENCES}

Bolles, R. C. Species-specific defense reactions and avoidance learning. Psychological Review, 1970, 77, 32-48.

Bolles, R. C. Reinforcement, expectancy, and learning. Psychological Review, 1972, 79, 394-409.

Bolles, R. C. The role of stimulus learning in defensive behavior. In S. H. Hulse, H. Fowler, \& W. K. Honig (Eds.), Cognitive processes in animal behavior. Hillsdale, N.J: Erlbaum, 1978.

Catania, A. C. Learning. Englewood Cliffs, N.J: Prentice-Hall, 1979.

Davis, S. F., \& Rossheim, S. A. Defensive burying as a function of insulin-induced hypoglycemia and type of aversive stimulation. Bulletin of the Psychonomic Society, 1980, 16, 229-231.

Gormezano, I., \& Moore, J. W. Classical conditioning. In N. H. Marx (Ed.), Learning processes. Toronto: Collier-MacMillan, 1969.

Heth, D. C., \& Rescorla, R. A. Simultaneous and backward fear conditioning in the rat. Journal of Comparative and Physiological Psychology, 1973, 82, 434-443.

Hudson, B. B. One-trial learning in the domestic rat. Genetic Psychology Monographs, 1950, 41, 99-145.

Huld, C. L. Principles of behavior. New York: Appleton-CenturyCrofts, 1943.

Keith-Lucas, T., \& Gutrman, N. Robust single-trial delayed backward conditioning. Journal of Comparative and Physiological Psychology, 1975, 88, 468-476.

KIMBLe, G. A. Hilgard and Marquis' conditioning and learning. New York: Appleton-Century-Crofts, 1961.

Mackintosh, N. J. The psychology of animal learning. New York: Academic Press, 1974.

Mahoney, W. J., \& Ayres, J. J. B. One-trial simultaneous and backward fear conditioning as reflected in conditioned suppression of licking in rats. Animal Learning \& Behavior, 1976, 4, 357-362.

Pinel, J. P. J., \& Treit, D. Burying as a defensive response in rats. Journal of Comparative and Physiological Psychology, 1978, 92, 708-712.

Pinel, J. P. J., Treit, D., \& Wilkie, D. M. Stimulus control 
of defensive burying in the rat. Learning and Motivation, 1980, 11, 150-163.

Rescorla, R. A. Pavlovian conditioning and its proper control procedures. Psychological Review, 1967, 74, 71-80.

Rescorla, R. A., \& WAgner, A. R. A theory of Pavlovian conditioning: Variations in the effectiveness of reinforcement and nonreinforcement. In A. H. Black \& W. F. Prokasy (Eds.), Classical conditioning II: Current research and theory. New York: Appleton-Century-Crofts, 1972.

Schwartz, B. Psychology of learning and behavior. New York: Norton, 1978.

Shurtleff, D., \& Ayres, J. J. B. One-trial backward excitatory fear conditioning in rats: Acquisition, retention, extinction, and spontaneous recovery. Animal Learning \& Behavior, 1981, 9, 65-74.
Spetch, M. L., Wilkie, D. M., \& Pinel, J. P. J. Backward conditioning: A reevaluation of the empirical evidence. Psychological Bulletin, 1981, 89, 163-175.

Terlecki, L. J., Pinel, J. P. J., \& Treit, D. Conditioned and unconditioned defensive burying in the rat. Learning and Motivation, 1979, 10, 337-350.

Terrace, H. S. Classical conditioning. In J. A. Nevin \& G. S. Reynolds (Eds.), The study of behavior: Learning, motivation, emotion, and instinct. Glenview, Ill: Scott, Foresman, 1973.

WAgner, A. R., \& TERRY, W. S. Backward conditioning to a CS following an expected vs. a surprising UCS. Animal Learning \& Behavior, 1975, 3, 370-374.

(Received for publication November 3, 1981.) 